\title{
Trichostatin A attenuates oxidative stress-mediated myocardial injury through the FoxO3a signaling pathway
}

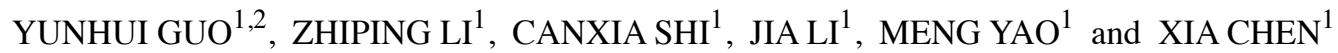 \\ ${ }^{1}$ Department of Pharmacology, College of Basic Medical Sciences, Jilin University, Changchun, \\ Jilin 130021; ${ }^{2}$ Department of Pharmacology, Jiamusi College, Heilongjiang University of \\ Traditional Chinese Medicine, Jiamusi, Heilongjiang 150040, P.R. China
}

Received July 2, 2016; Accepted August 3, 2017

DOI: $10.3892 / \mathrm{ijmm} .2017 .3101$

\begin{abstract}
Trichostatin A (TSA), a histone deacetylase inhibitor, is widely used as an anticancer drug. Recently, TSA has been shown to exert a protective effect on ischemia/reperfusion (I/R) injury; however, the underlying mechanisms remain unclear. Forkhead box O3a (FoxO3a), a unique FoxO family member, has been shown to attenuate myocardial injury by increasing resistance to oxidative stress in mice. The present study aimed to investigate whether TSA exerts its cardioprotective effects through the FoxO3a signaling pathway. For this purpose, healthy male Wistar rats were pre-treated with TSA for 5 days before they were subjected to ligation/relaxation of the left anterior descending branch of the coronary artery and to $30 \mathrm{~min}$ of ischemia, followed by $24 \mathrm{~h}$ of reperfusion. The activities of creatine kinase (CK), lactate dehydrogenase (LDH), aspartate aminotransferase (AST) and superoxide diamutase (SOD), as well as the malondialdehyde (MDA) levels were examined. The H9c2 rat myocardial cell line was cultured in 10\% FBS-containing DMEM for $24 \mathrm{~h}$. The cells were incubated with/without TSA $(50 \mathrm{nmol} / \mathrm{l})$ for $1 \mathrm{~h}$ and then incubated with/without $\mathrm{H}_{2} \mathrm{O}_{2}(400 \mu \mathrm{M})$ for $2 \mathrm{~h}$. Reactive oxygen species (ROS) and mitochondrial membrane potential $(\Delta \psi m)$ were measured by probe staining in the H9c2 cells. The expression of FoxO3a, mitochondrial SOD2 and catalase was quantified by western blot analysis. The levels of $\mathrm{H} 3$ and $\mathrm{H} 4$ acetylation of the FoxO3a promoter region were examined by chromatin immunoprecipitation assay. TSA significantly reduced the myocardial infarct size and the activities of serum LDH, AST and CK in the rats. TSA also decreased the levels of MDA and
\end{abstract}

Correspondence to: Professor Xia Chen, Department of Pharmacology, College of Basic Medical Sciences, Jilin University, 126 Xinmin Street, Changchun, Jilin 130021, P.R. China

E-mail: chenx@jlu.edu.cn

Abbreviations: TSA, trichostatin A; I/R, ischemia/reperfusion; MI, myocardial infarction; TTC, 2,3,5-triphenyltetrazolium chloride; AST, aspartate aminotransferase; CK, creatine kinase; LDH, lactate dehydrogenase; ROS, reactive oxygen species; $\Delta \psi m$, mitochondrial membrane potential; SOD2, superoxide dismutase 2

Key words: trichostatin A, myocardial ischemia/reperfusion, forkhead box O3a, mitochondrial membrane potential, acetylation increased the activities of SOD in the myocardial tissue of the rats. Consistent with the reduced injury to the TSA-treated rats, TSA significantly reduced the $\mathrm{H}_{2} \mathrm{O}_{2}$-induced levels of ROS and increased $\Delta \psi m$. In addition, TSA increased the expression of FoxO3a, SOD2 and catalase, which may be related to increasing the level of $\mathrm{H} 4$ acetylation of the FoxO3a promoter region. Our results thus revealed that TSA protected the myocardium from oxidative stress-mediated damage by increasing $\mathrm{H} 4$ acetylation of the FoxO3a promoter region, and the expression of FoxO3a, SOD2 and catalase.

\section{Introduction}

Acute myocardial infarction (MI) is a tremendous threat to the life and health of the population. However, accumulating evidence indicates that directly restoring the blood supply through reperfusion following $\mathrm{MI}$ in fact aggravates the damage. This additional damage, namely ischemia/reperfusion (I/R) injury (1-3) is a hotspot of current research. Recent studies have reported that the pathogenesis of myocardial $I / R$ injury is multifactorial, involving the dysfunction of energy metabolism, robust reactive oxygen species (ROS) generation, cell calcium overload, inflammatory responses and apoptosis (4-8). Oxidative stress resulting from ROS may be a significant feature in the development of cardiac injury induced by I/R (9); however, the underlying regulatory mechanisms of cardiac oxidative stress resistance remain unclear. Forkhead box O3a (FoxO3a) plays an important role in metabolism, cell survival and resistance to oxidative stress in multiple cell types (10). However, its role in regulating tolerance to cardiac stress remains to be fully elucidated. FoxO3a interacts with the promoter of the superoxide diamutase 2 (SOD2) gene at a specific binding site in vascular smooth muscle cells (11); however, whether it influences SOD2 expression in cardiomyocytes has not yet been reported, at leas to the best of our knowledge.

The nucleosome is the basic structural unit of eukaryotic chromatin, which is made up of histones and DNA. Histone acetylation modification affects chromatin packaging and gene expression (12). Transcriptional activity is found in areas where the histone acetylation level is higher, and transcriptional silencing in areas where the histone acetylation level is usually lower (13). The acetylation of histone is a reversible process, which is regulated by histone acetyltransferases (HATs) and 
histone deacetylases (HDACs) (14), and the dynamic balance between them plays a very important role in eukaryotic gene regulation (15). It has been demonstrated that HDAC inhibitors play a protective role in cardiovascular diseases, such as cardiac hypertrophy, inflammatory responses and heart failure (16).

Trichostatin A (TSA), a histone deacetylase inhibitor, is used as a promising anticancer agent $(17,18)$. Our previous study demonstrated that TSA attehnuated myocardial I/R injury (19); however, the underlying mechanisms remain to be elucidated. It has been shown that FoxO3a attehnuates myocardial injury by increasing resistance to oxidative stress in mice (20) and that the endogenous HDAC inhibitor, $\beta$-hydroxybutyrate, can increase histone acetylation at the FoxO3a promoters in 293 cells (21). We therefore speculated that the mechanisms through which TSA attenuates myocardial injury may be associated with FoxO3a. In the present study, we demonstrate that TSA attenuates myocardial injury by increasing resistance to oxidative stress. We further investigated whether the mechanisms involved in these effects are mediated through the FoxO3a signaling pathway.

\section{Materials and methods}

Ethical approval of the study protocol. The study was approved by the Ethics Committee of Jilin University, and all experimental procedures conformed to the guidelines for the Animal Care and Use Committee of Jilin University, Changchun, China.

Animals and model of myocardial $I / R$ in rats. A total of 80 healthy male Wistar rats (weighing, 180-220 g) were purchased from the Animal Centre of Jilin University (certificate number SCXK (JI) 2007-0003). In total 40 Wistar rats first were subjected to MI by ligating the left anterior descending branch of the coronary artery and to $30 \mathrm{~min}$ of ischemia, followed by $0,6,12$ or $24 \mathrm{~h}$ reperfusion in order to determine the effects at different time points on FoxO3a expression; 10 rats were used at each time point. The other 40 rats were randomly divided into 5 groups as follows: i) the sham-operated (control), treated with saline $(n=8)$; ii) the I/R group, in which rats were subjected to $\mathrm{I} / \mathrm{R}$ and treated with saline $(\mathrm{n}=8)$; iii) the TSA 1 group, in which rats were subjected to I/R and treated with $0.2 \mathrm{mg} / \mathrm{kg}$ (I/ $\mathrm{R}+\mathrm{T} 1)(\mathrm{n}=8)$; iv) the TSA 2 group, in which rats were subjected to $\mathrm{I} / \mathrm{R}$ and treated with $0.1 \mathrm{mg} / \mathrm{kg}(\mathrm{I} / \mathrm{R}+\mathrm{T} 2)(\mathrm{n}=8)$; and $\mathrm{v})$ the TSA 3 group, in which rats were subjected to $I / R$ and treated with $0.05 \mathrm{mg} / \mathrm{kg}(\mathrm{I} / \mathrm{R}+\mathrm{T} 3)(\mathrm{n}=8)$. The rats in the 5 groups were injected with TSA or saline by intraperitoneal administration once daily for 5 days. Standard rat chow and water were available ad libitum. On day 5, the animals in the 5 groups underwent $30 \mathrm{~min}$ left anterior descending (LAD) coronary artery ligation and $24 \mathrm{~h}$ of reperfusion according to the method previously described by Li et al (22). Briefly, the rats were anesthetized by an intraperitoneal injection of $10 \%$ chloral hydrate $(0.35 \mathrm{~g} / \mathrm{kg})$ before undergoing a thoracotomy. After ensuring the appropriate depth of anesthesia, the rats were intubated without incision using a rodent ventilator. The thoracic cavity was opened and the heart was rapidly exposed. The left anterior descending coronary artery (LAD) was ligated by a 6-0 silk suture (2-3 mm below the left auricle) and the chest was immediately closed. Successful I/R injury was monitored by standard lead II electrocardiography (ECG). The sham- operated rats only underwent the suture around the LAD, but were not ligated. Following reperfusion, the myocardial infarct size, serum myocardium enzyme activities and protein expression were evaluated.

Cell culture. The H9c2 rat myocardial cell line was obtained from the Cell Bank of Chinese Academy of Sciences (Shanghai, China). The cells were cultured in a $5 \% \mathrm{CO}_{2}$ humidified atmosphere at $37^{\circ} \mathrm{C}$ in $10 \%$ fetal bovine serum (FBS)-containing Dulbecco's modified Eagle's medium (DMEM). The cells were seeded in 6-well-plates for $24 \mathrm{~h}$ and were then incubated with/without TSA (50 nmol/l) for $1 \mathrm{~h}$ and then incubated with/ without $\mathrm{H}_{2} \mathrm{O}_{2}(400 \mu \mathrm{M})$ for $2 \mathrm{~h}$.

Chemicals and antibodies. TSA was purchased from TCI Development Company Ltd. (Shanghai, China). Polyclonal rabbit antibody against catalase was purchased from Abcam (ab76110; Cambridge, CA, USA). Polyclonal rabbit antibodies to FoxO3a (12829) and SOD2 (13141) were purchased from Cell Signaling Technology (Danvers, MA, USA). Glyceraldehyde 3-phosphate dehydrogenase (GAPDH; 60004-1-lg) antibody was from the ProteinTech Group, Inc. (Chicago, IL, USA). Goat anti-rabbit IgG horseradish peroxidase (HRP)-conjugated secondary antibody (A0208), goat anti-mouse IgG HRP-labeled secondary antibody (A0216), the cell counting kit-8 (CCK-8), ROS assay kit and mitochondrial membrane potential detection kit were from the Beyotime Institute of Biotechnology (Jiangsu, China). The EZ ChIP ${ }^{\text {тм }}$ Chromatin Immunoprecipitation kit was purchased from Millipore Corp. (Billerica, MA, USA). Enhanced chemiluminescence (ECL) detection reagents were from Thermo Fisher Scientific (Waltham, MA, USA). Other chemical reagents were commercially available and analytically pure.

Cell viability. The viability of the H9c2 cells (in 96-well plates) was measured by CCK-8 assay according to the manufacturer's instructions. Briefly, the cells were exposed to $\mathrm{H}_{2} \mathrm{O}_{2}$ at various concentrations for different durations. CCK-8 solution $(10 \mu \mathrm{l})$ was added followed by further incubation for $2 \mathrm{~h}$ and the absorbance were measured at $450 \mathrm{~nm}$ using a microplate reader (Infinite M200 PRO; Tecan Corp., Mannedorf, Switzerland).

Measurement of myocardial infarct size (MIS). Following 0, 6, 12 and $24 \mathrm{~h}$ of reperfusion, the animals were euthanized and the hearts were rapidly removed. The MIS size was assessed by the 2,3,5-triphenyltetrazolium chloride (TTC) method as previously described (23). Briefly, the excised hearts were washed using $0.9 \%$ saline. The right ventricular tissues were removed and left ventricles were frozen and stored at $-20^{\circ} \mathrm{C}$ for $5 \mathrm{~min}$ and then were sliced into 1 -mm-thick sections, giving 5 slices of equal thickness along the long axis from the apex to the base. The slices were incubated for 15-30 min in TTC at $\mathrm{pH} 7.4$ at $37^{\circ} \mathrm{C}$ to identify the viable myocardium stained red, while the infarct tissue remained white. The slices were fixed in $10 \%$ formaldehyde solution and photographed with a digital camera. Areas stained in red and white were measured by a BI-2000 Medical Image Analysis System (Chengdu TME Technology, Chengdu, China). The infarct size was calculated using the following equation: \%Infarct volume = infarct volume/total left ventricle volume x $100 \%$. 
Measurement of myocardial enzyme [creatine kinase (CK), lactate dehydrogenase $(\mathrm{LDH})$ and aspartate aminotransferase $(A S T)]$ activities in serum. At the end of the experiment, blood samples were obtained from the abdominal aorta, incubated at $37^{\circ} \mathrm{C}$ for $30 \mathrm{~min}$ and then centrifuged at 3,000 rpm for $10 \mathrm{~min}$. The supernatant from each group was collected and frozen at $-80^{\circ} \mathrm{C}$ for further analysis. The activities of $\mathrm{CK}, \mathrm{LDH}$ and AST were measured using CK, LDH and AST kits (Jiancheng Bioengineering Institute, Nanjing, China) with an automatic biochemistry analyzer (EOS880; Hospitex Diagnostics, Italy) according to the manufacturer's instructions.

Measurement of malondialdehyde (MDA) levels and SOD activities. At the end of the experiment, the myocardial tissue was homogenated for $5 \mathrm{~min}$ in the ice and then centrifuged at $2,000 \mathrm{rpm}$ for $5 \mathrm{~min}$. The supernatant from each group was collected for measuring the levels of MDA and the activities of SOD using respective kits (Jiancheng Bioengineering Institute).

Western blot analysis. Proteins were separated by 5-18\% sodium dodecylsulfate polyacrylamide gel electrophoresis (SDS-PAGE) and transferred onto polyvinylidene fluoride membranes. The membranes were blocked with 5\% skimmed dry milk for $2 \mathrm{~h}$ at room temperature and washed 3 times in Tris-buffered saline with Tween (TBST); the membranes were then incubated with the primary antibodies to FoxO3a, SOD2, catalase and GAPDH overnight at $4^{\circ} \mathrm{C}$. After washing with TBST again, HRP-labeled secondary antibodies goat anti-rabbit $(1: 1,000)$ or goat anti-mouse $(1: 2,000)$ were added followed by incubation for $1.5 \mathrm{~h}$ at room temperature. Immunoblots were developed by ECL detection kits and the bands were quantified by Quantity One software.

Immunofluorescence staining. The cultured H9c2 cells were fixed with $4 \%$ paraformaldehyde for $30 \mathrm{~min}$ and then washed 3 times in phosphate-buffred saline (PBS). Blocking solutions ( $0.2 \%$ Triton $\mathrm{X}-100$ and sheep serum in PBS) were added to the fixed cells followed by incubation for $30 \mathrm{~min}$ at $37^{\circ} \mathrm{C}$. The cells were then incubated with primary antibody against FoxO3a overnight at $4^{\circ} \mathrm{C}$. After washing with PBS, the appropriate secondary antibody was added followed by incubation for $1 \mathrm{~h}$ in the dark at room temperature. The nuclei were then stained with Hoechst 33342 for $20 \mathrm{~min}$. After washing with PBS, immunofluorescence was examined under a fluorescence microscope.

Measurement of ROS production. Intracellular ROS of H9c2 was measured by 2'7'-dichlorodihydrofluorescein diacetate (DCFH-DA) as a fluorescent probe according to the manufacturer's instructions. Briefly, H9c2 cells were loaded with DCFH-DA $(10 \mu \mathrm{M})$ for $30 \mathrm{~min}$ at $37^{\circ} \mathrm{C}$ and washed 3 times with serum-free medium. The fluorescence image was observed under a fluorescence microscope.

Detection of mitochondrial membrane potential $(\Delta \psi m)$. The dye, JC-1, was used as a fluorescent probe to detect $\Delta \psi m$ as previously described (24). CCCP (10 mM) provided in the kit was added to the cell culture medium at 1:1,000 for $20 \mathrm{~min}$ at room temperature, then the $\mathrm{H} 9 \mathrm{c} 2$ cells were incubated with JC-1 dye $(10 \mu \mathrm{M})$ for $30 \mathrm{~min}$ at $37^{\circ} \mathrm{C}$ and washed twice with
JC-1 dyeing buffer (1X). The red and green fluorescence were observed under a fluorescence microscope.

Chromatin immunoprecipitation assay. Chromatin immunoprecipitation assay (25) was performed in accordance with the manufacturer's instructions with slight modifications. In brief, protein/DNA complexes of $\mathrm{H} 9 \mathrm{c} 2$ cells $\left(5 \times 10^{6}\right)$ were crosslinked with formaldehyde and were sonicated to 200-1000 bp of DNA fragments. The crosslinked protein/DNA was then immunoselected with specific antibodies and the protein/DNA complexes were then eluted. Protein-DNA crosslinks were reversed during incubation at $65^{\circ} \mathrm{C}$ and DNA was purified to subject to quantitative PCR using the following primers: 5'-AAAGGCATCCCAAGGTAT-3' (forward) and 5'-CCA GCTCTACAGCTCGTAC-3' (reverse).

Statistical analyses. Data are shown as the means \pm SD. Analysis of variance (ANOVA) was used to compare quantitative variables between more than 2 groups. Intergroup differences were assessed by the Chi-square test and Student's t-test for quantitative variables. A p-value $<0.05$ (two-sided) was considered statistically significant. Data were analyzed with GraphPad Prism 5.0 software.

\section{Results}

Oxidative stress induces myocardial injury. In order to observe the effects of oxidative stress on $\mathrm{H} 9 \mathrm{c} 2$ rat myocardial cells, $\mathrm{H}_{2} \mathrm{O}_{2}$ was used as an inducer. The results from CCK- 8 assay revealed that cell viability decreased following exposure to $\mathrm{H}_{2} \mathrm{O}_{2}$ in a dose- and time-dependent manner. The cell survival rate at $\mathrm{H}_{2} \mathrm{O}_{2} 400 \mu \mathrm{M}$ for $2 \mathrm{~h}$ was $53.96 \pm 5.6 \%$ (Fig. 1A), compared with the control group, and the cell viability was significantly decreased $(\mathrm{p}<0.01)$. Subsequently, intracellular ROS levels were detected using the DCFH-DA probe; the strength of the green fluorescence directly reflects intracellular ROS. The levels of ROS increased gradually following exposure to $\mathrm{H}_{2} \mathrm{O}_{2}$ compared with the untreated group, and the fluorescence intensity was significantly increased at $2 \mathrm{~h}$ (Fig. 1B).

FoxO3a is downregulated in oxidative stress-induced myocardial injury. To investigate the role of FoxO3a under myocardial oxidative stress conditions, we performed the experiments in vitro and in vivo. We examined the expression of FoxO3a in the $\mathrm{H} 9 \mathrm{c} 2$ cells exposed to $\mathrm{H}_{2} \mathrm{O}_{2}$ at $400 \mu \mathrm{M}$ for different periods of time. A significant downregulation in FoxO3a expression was observed following exposure of the cells to $\mathrm{H}_{2} \mathrm{O}_{2}$ at $400 \mu \mathrm{M}$ for $2 \mathrm{~h}$ (Fig. 2A). We also detected the expression of FoxO3a in rats subjected to $\mathrm{MI}$ and $30 \mathrm{~min}$ of ischemia, followed by 0 , 6,12 or $24 \mathrm{~h}$ of reperfusion. The expression of FoxO3a was also decreased in the myocardial tissue in the rats with $\mathrm{I} / \mathrm{R}$ injury (Fig. 2B).

TSA attenuates myocardial injury mediated by oxidative stress. To examine the effects of TSA on myocardial injury mediated by oxidative stress, we performed the experiments in vitro and in vivo. We measured the MIS by the TTC method. Compared with the I/R group, the MIS was significantly reduced in the TSA $0.2 \mathrm{mg} / \mathrm{kg}$ (T1)- and $0.1 \mathrm{mg} / \mathrm{kg}$ (T2)-treated groups, from 53.36 to $15.89 \%(\mathrm{p}<0.01)$ and $20.06 \%(\mathrm{p}<0.001)$ respec- 

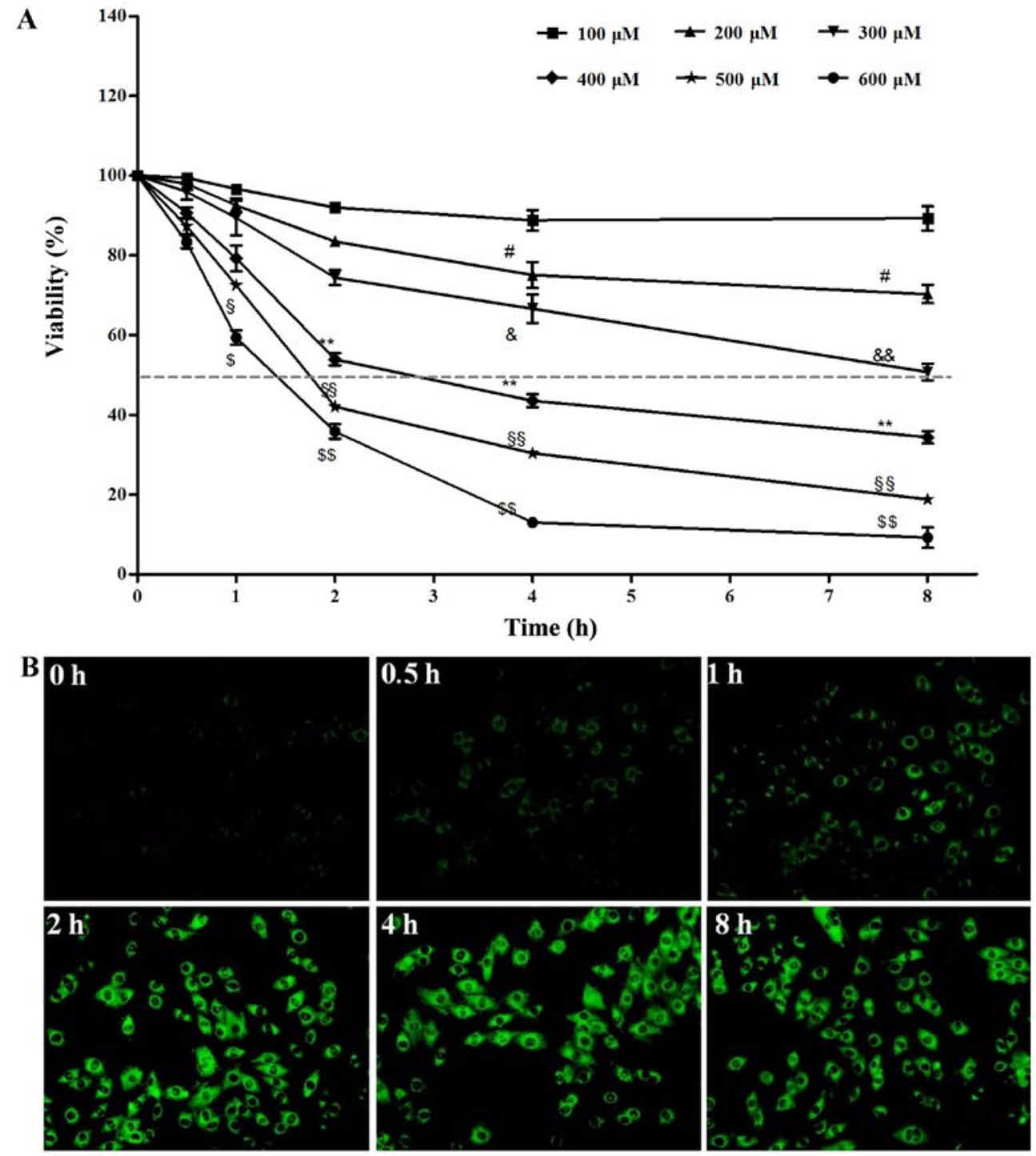

Figure 1. Oxidative stress induces myocardial injury. (A) Viability of $\mathrm{H} 9 \mathrm{c} 2$ cells exposed to $\mathrm{H}_{2} \mathrm{O}_{2}$ at various concentrations for different periods of time are shown. Data are the means $\pm \mathrm{SD} ;{ }^{\#, \&, s} \mathrm{p}<0.05$ and \&\&\&,*,\&,\$\$ $\mathrm{p}<0.01$ vs. untreated cells. (B) Images of reactive oxygen species (ROS) production by H9c2 cells exposed to $\mathrm{H}_{2} \mathrm{O}_{2}(400 \mu \mathrm{M})$ are shown (magnification, $\mathrm{x} 200$ ).

tively; however, the MIS between the I/R and TSA $0.05 \mathrm{mg} /$ $\mathrm{kg}$ (T3)-treated groups was not significantly altered (Fig. 3A). Subsequently, in order to evaluate the extent of myocardial injury in the rats, we measured the activities of CK, LDH and AST in serum after $24 \mathrm{~h}$ of reperfusion. In accordance with MIS, TSA significantly decreased the activities of CK, LDH and AST in serum (Fig. 3B). In addition, the MDA level was decreased and the SOD activity was increased in the TSA-treated groups compared with those in the sham-operated group (Fig. 3C).

In order to investigate whether TSA reduces the ROS levels following exposure of the $\mathrm{H} 9 \mathrm{c} 2$ cells to $\mathrm{H}_{2} \mathrm{O}_{2}$, intracellular ROS production was detected by the DCFH-DA probe. Compared with the $\mathrm{H}_{2} \mathrm{O}_{2}$-exposed group, treatment with TSA reduced the intracellular ROS level (Fig. 3D). It has been reported that oxidative stress induces mitochondrial dysfunction (26). Thus, in this study, to investigate the protective effect of TSA against oxidative stress-induced mitochondrial damage, $\Delta \psi m$ in the $\mathrm{H} 9 \mathrm{c} 2$ cells was assessed using the JC- 1 probe. The $\Delta \psi m$ of the $\mathrm{H} 9 \mathrm{c} 2$ cells declined markedly following exposure to $\mathrm{H}_{2} \mathrm{O}_{2}$, whereas treatment with TSA increased the $\Delta \psi m$ in the H9c2 cells (Fig. 3E).

Effect of TSA on the expression of FoxO3a. FoxO3a is an important regulator of the resistance to oxidative stress and the downregulation of FoxO3a increases cell death in response to oxidative stress in human chondrocytes (27). Resveratrol, a potent antioxidant, has previously been demonstrated to protect photoreceptor cells from apoptosis by upregulating the FoxO family in experimental retinal detachment (28). Our experimental results revealed that the expression of FoxO3a in the $\mathrm{H} 9 \mathrm{c} 2$ cells was markedly reduced in the presence of $\mathrm{H}_{2} \mathrm{O}_{2}$ compared with that of the control group $(\mathrm{p}<0.01)$. However, TSA elicited a significant increase in FoxO3a expression compared with the $\mathrm{H}_{2} \mathrm{O}_{2}$ alone-treated group ( $<<0.01$ ) (Fig. 4A and B). In line with the in vitro experimental results, TSA increased the expression of FoxO3a following $24 \mathrm{~h}$ of reperfusion in rats (Fig. $4 C ; p<0.01$ vs. sham-operated group; $p<0.01$ vs. I/R group). 
A
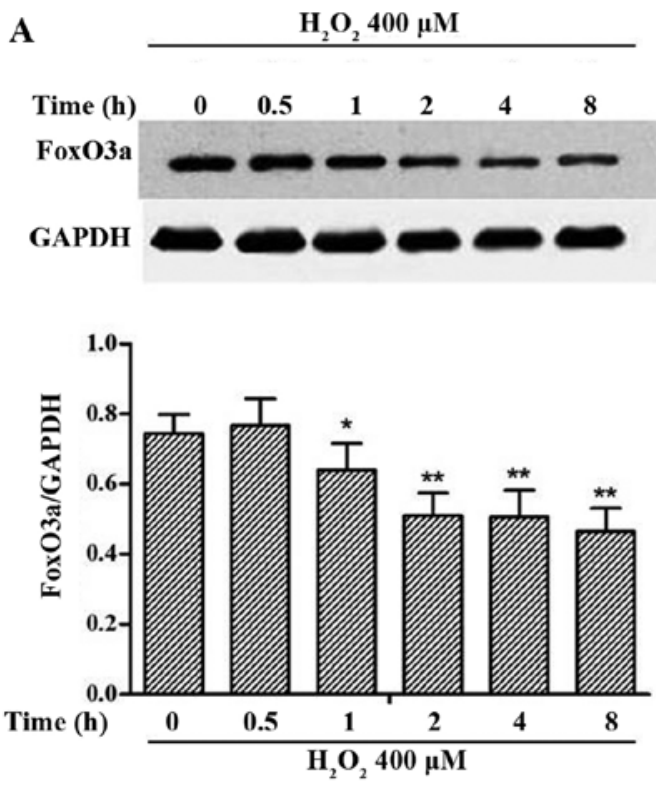

B
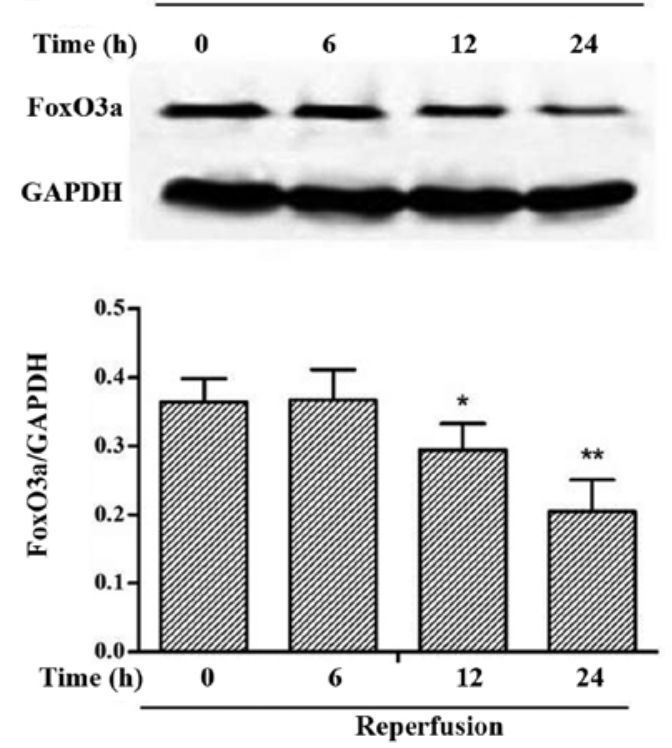

Figure 2. Forkhead box O3a (FoxO3a) is downregulated in oxidative stress-induced myocardial injury. (A) Effects of exposure to $400 \mu \mathrm{M} \mathrm{H}_{2} \mathrm{O}_{2}$ for $0,0.5,1,2,4$ and $8 \mathrm{~h}$ on the expression of Foxo3a in $\mathrm{H} 9 \mathrm{c} 2$ cells. (B) FoxO3a expression after $30 \mathrm{~min}$ of ischemia followed by 0, 6, 12 and $24 \mathrm{~h}$ of reperfusion in the rats. Data are the means $\pm \mathrm{SD} ;{ }^{*} \mathrm{p}<0.05$ and ${ }^{* *} \mathrm{p}<0.01$ vs. $0 \mathrm{~h}$.

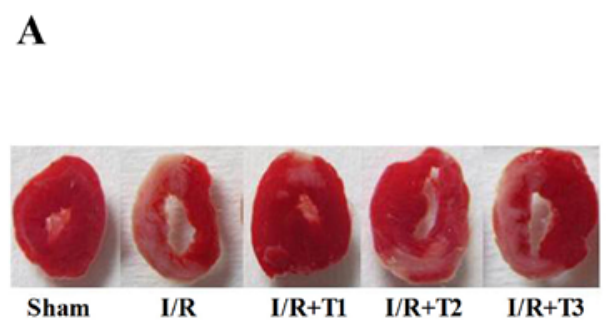

B
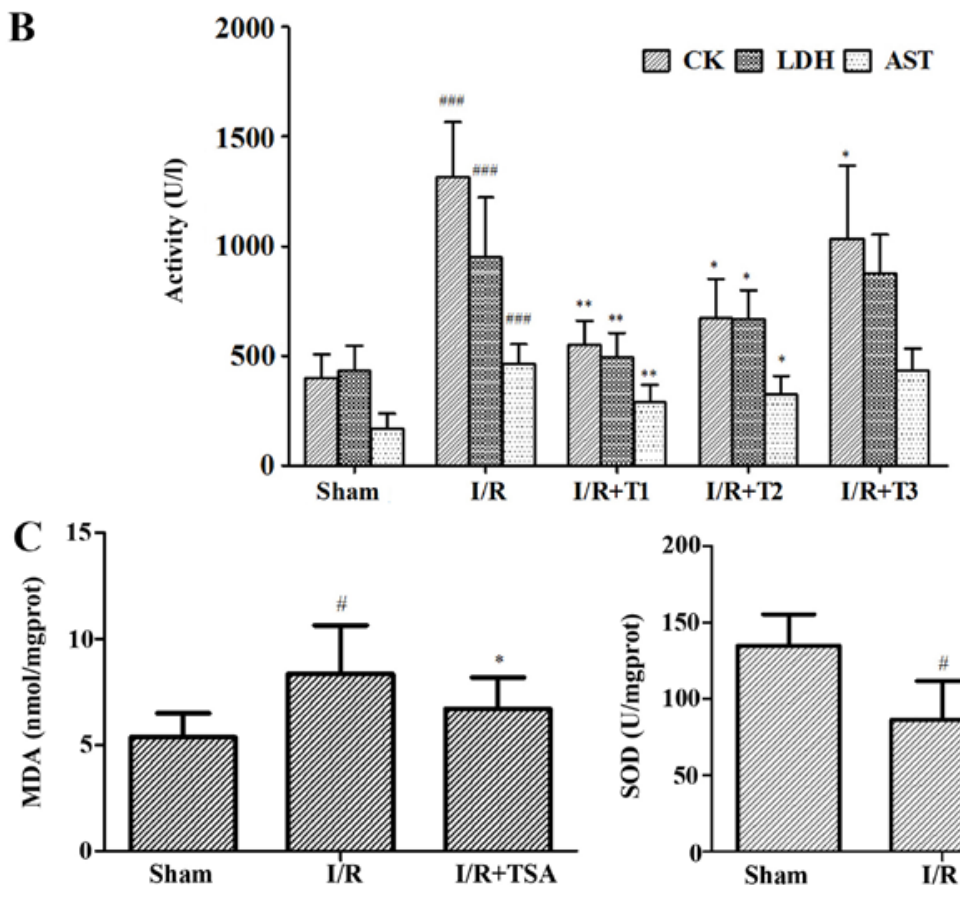
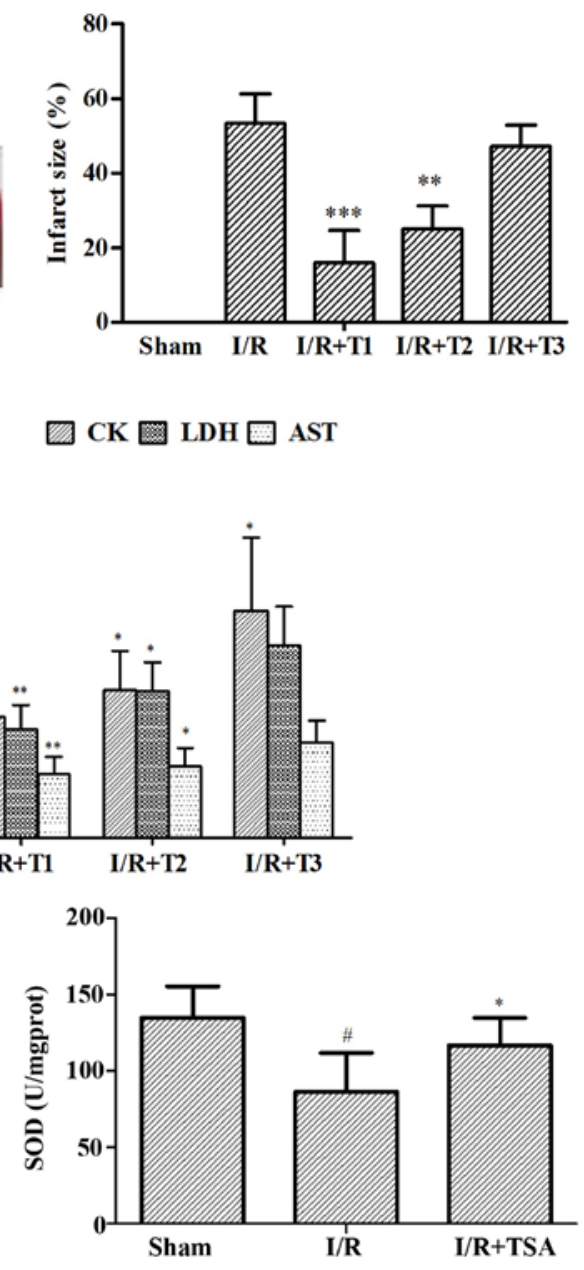

Figure 3. Trichostatin A (TSA) attenuates myocardial injury mediated by oxidative stress. (A) The myocardial infarct size was assessed by TTC. Rat hearts were subjected to $30 \mathrm{~min}$ of ischemia followed by $24 \mathrm{~h}$ of reperfusion $(\mathrm{n}=8)$ and graphs show the myocardial infarct size (infarct volume/left ventricular volume). ${ }^{* *} \mathrm{p}<0.01$ and ${ }^{* * *} \mathrm{p}<0.01$, vs. I/R group. (B) The activities of CK, LDH and AST in the serum of rats whose hearts were subjected to 30 min of ischemia followed by $24 \mathrm{~h}$ of reperfusion were measured ( $\mathrm{n}=8)$. T1, TSA $0.2 \mathrm{mg} / \mathrm{kg} ;$ T2, TSA $0.1 \mathrm{mg} / \mathrm{kg}$; and T3, TSA $0.05 \mathrm{mg} / \mathrm{kg}$. Data are the means $\pm \mathrm{SD} ;{ }^{*} \mathrm{p}<0.05$ and ${ }^{* *} \mathrm{p}<0.01 \mathrm{vs}$. ischemia/ reperfusion (I/R) group; ${ }^{\# \# \# ~} \mathrm{p}<0.001 \mathrm{v}$. sham-operated (sham) group. (C) The levels of malondialdehyde (MDA) and the activities of superoxide diamutase (SOD) of rats whose hearts were subjected to $30 \mathrm{~min}$ of ischemia followed by $24 \mathrm{~h}$ of reperfusion were measured (n=8). Data are the means $\pm \mathrm{SD}$; ${ }^{*} \mathrm{p}<0.05$ and vs. I/R group; " $\mathrm{p}<0.05$, vs. sham group. 
D
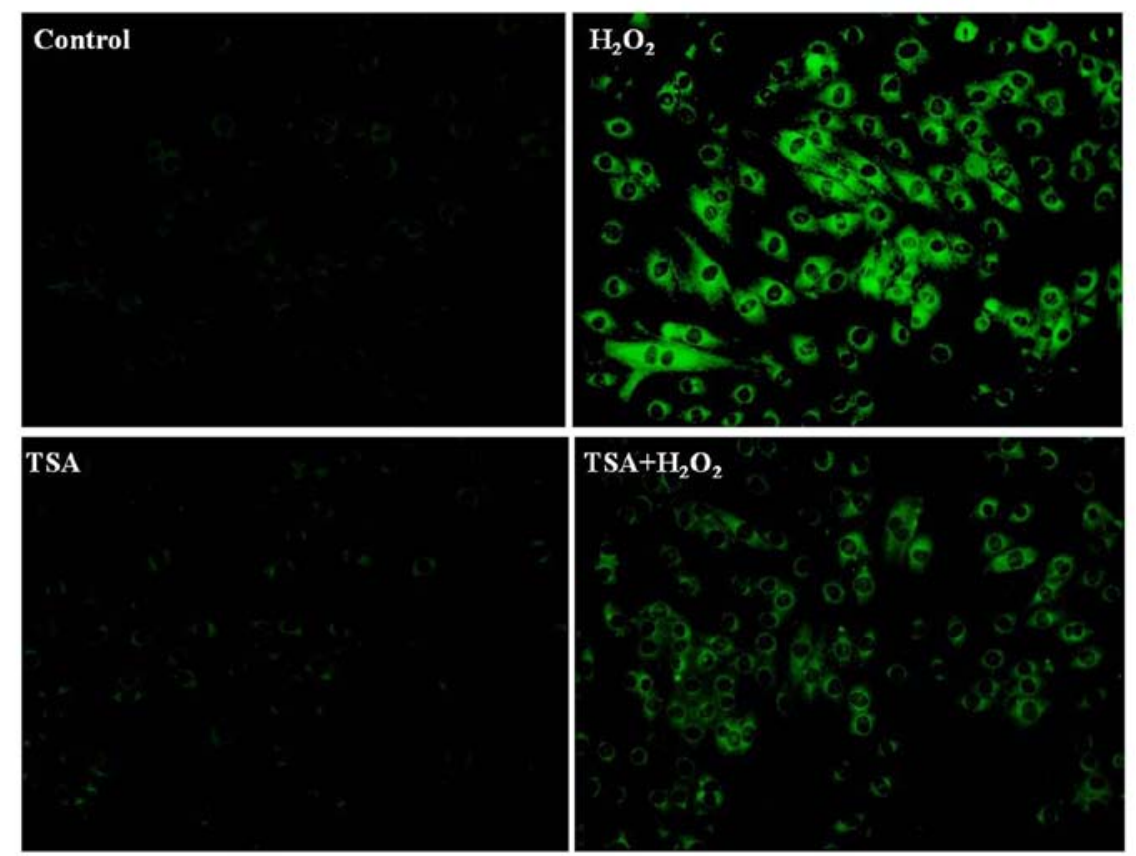

$\mathbf{E}$

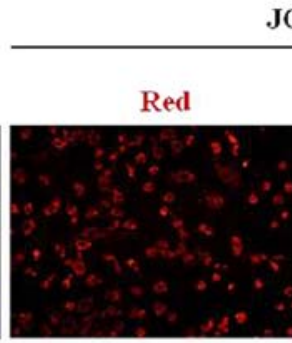

JC-1
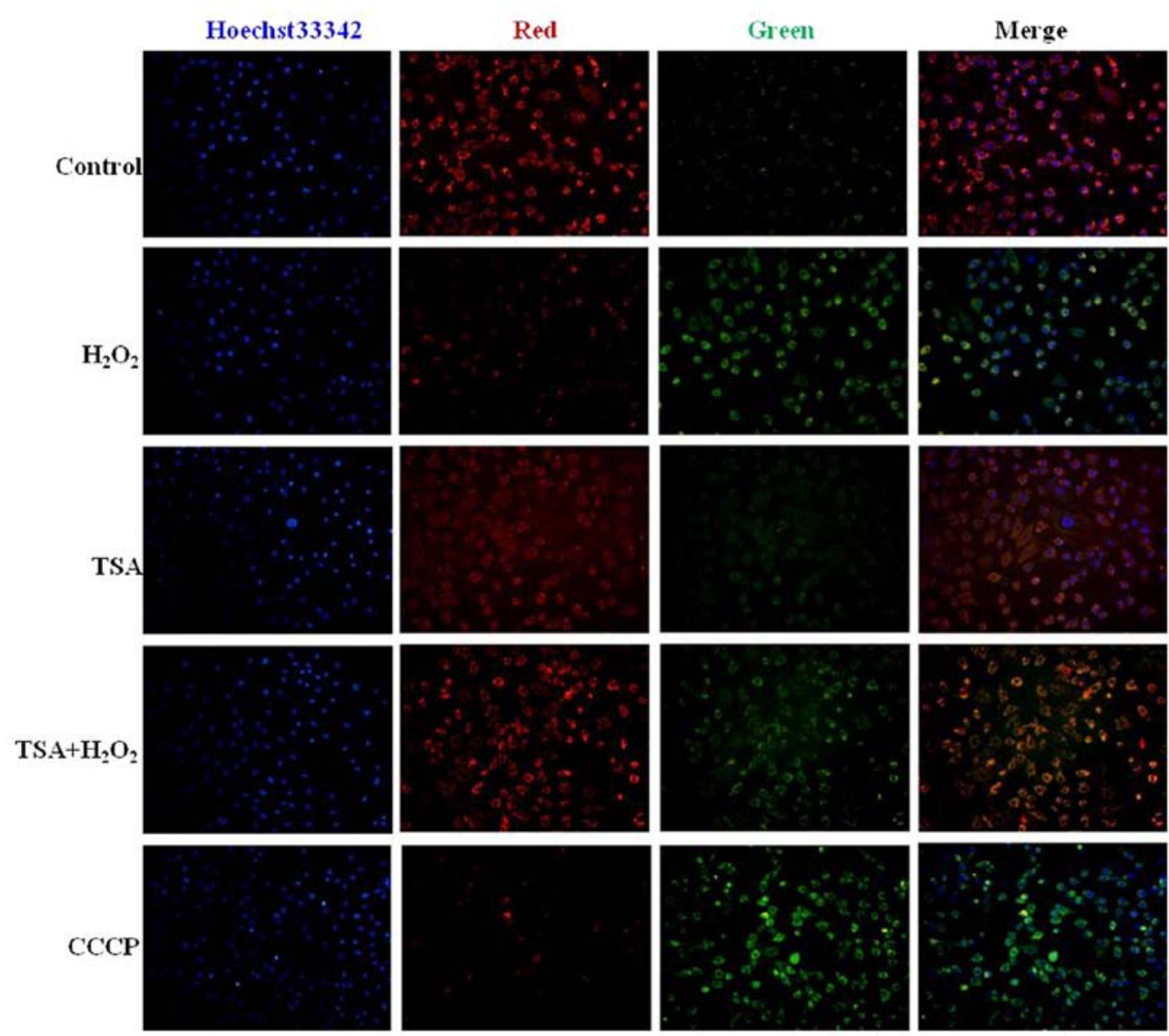

Figure 3. Continued. (D) Reactive oxygen species (ROS) production was evaluated by the DCFH-DA probe following exposure or not of the H9c2 cells to $400 \mu \mathrm{M} \mathrm{H}_{2} \mathrm{O}_{2}$ for $2 \mathrm{~h}$ in the absence or presence of $50 \mathrm{nmol} / 1$ TSA in (magnification, x200). (E) $\Delta \psi m$ was assessed by using JC-1 probe in H9c2 cells using JC-1 staining treated with/without $400 \mu \mathrm{M} \mathrm{H}_{2} \mathrm{O}_{2}$ for $2 \mathrm{~h}$ in the absence or presence of $50 \mathrm{nmol} / 1 \mathrm{TSA}$ in $\mathrm{H} 9 \mathrm{c} 2$ cells are shown (magnification, $\mathrm{x} 100$ ), CCCP was used as a positive control.

Effect of TSA on SOD2 and catalase levels. Mitochondrial SOD and catalase as endogenous enzymes are known to be the target proteins of FoxO3a that contributes to their protective effects against oxidative stress $(29,30)$. The levels of SOD2 and 
$\mathbf{A}$
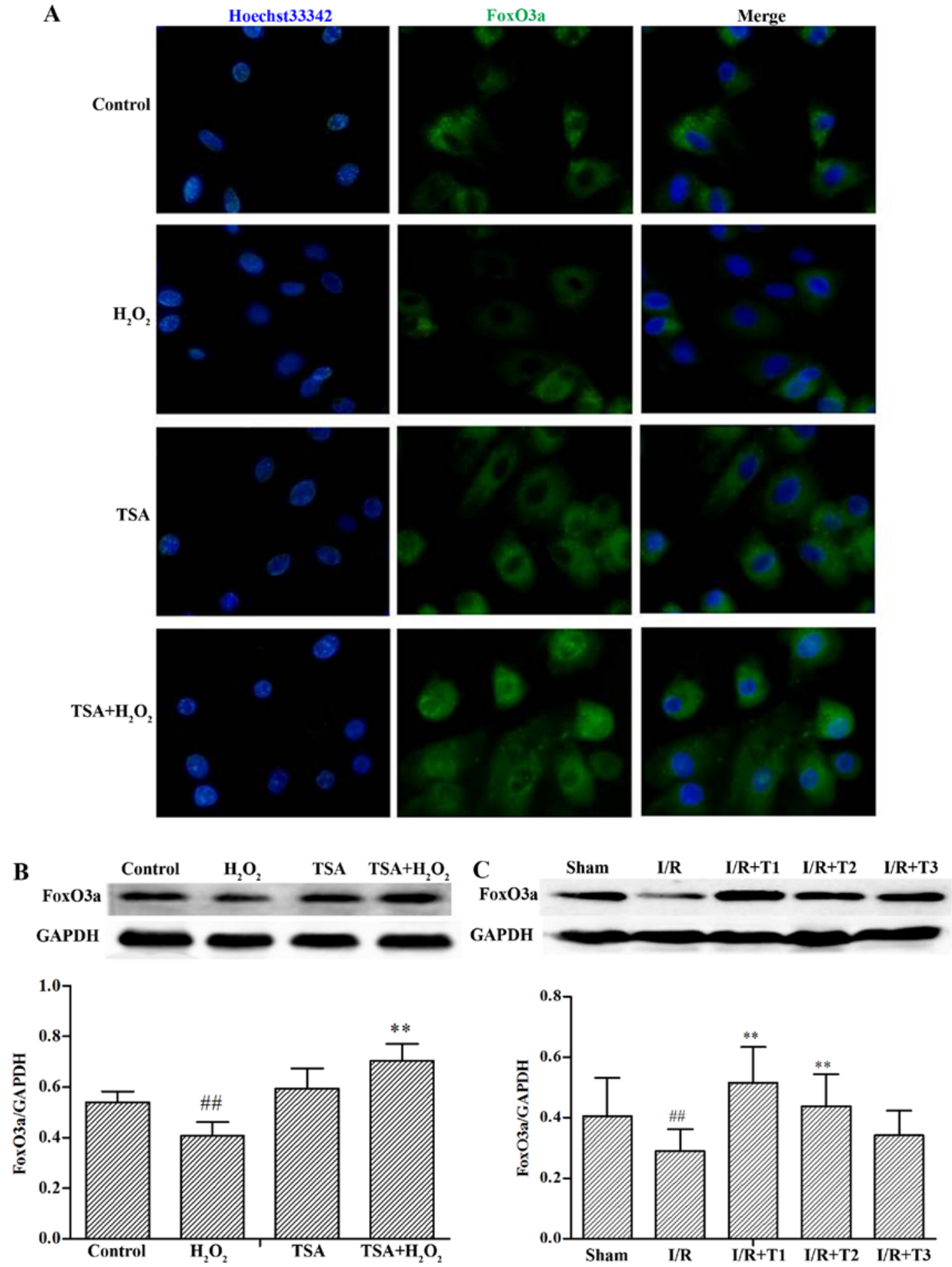

Figure 4. Effect of trichostatin A (TSA) on the expression of forkhead box O3a (FoxO3a). (A and B) Using immunofluorescence and western blot analysis to detect the expression of FoxO3a in $\mathrm{H} 9 \mathrm{c} 2$ cells. FoxO3a was significantly upregulated following treatment with $50 \mathrm{nmol} / 1 \mathrm{TSA}$ in the absence or presence of $\mathrm{H}_{2} \mathrm{O}_{2}$. Data are the means $\pm \mathrm{SD} ;{ }^{\# /} \mathrm{p}<0.01$ vs. control; ${ }^{* *} \mathrm{p}<0.01$ vs. $\mathrm{H}_{2} \mathrm{O}_{2}$. (C) TSA upregulated the expression of FoxO3a after ischemia for 30 min and $24 \mathrm{~h}$ of reperfusion in the rats. Data are the means $\pm \mathrm{SD} ;{ }^{\# \#} \mathrm{p}<0.01$ vs. sham-operated (sham) group ; ${ }^{* *} \mathrm{p}<0.01$ vs. ischemia/reperfusion (I/R) group.

catalase in the $\mathrm{H} 9 \mathrm{c} 2$ cells markedly decreased following exposure to $\mathrm{H}_{2} \mathrm{O}_{2}$, whereas treatment with TSA elicited a significant increase in SOD2 and catalase levels in the $\mathrm{H} 9 \mathrm{c} 2$ cells $(\mathrm{p}<0.01)$ compared with cells exposed to $\mathrm{H}_{2} \mathrm{O}_{2}$ alone (Fig. 5).

Effects of TSA on the acetylation levels of histone $\mathrm{H} 3$ and H4 in the promoter region of FoxO3a. To investigate whether TSA affects the levels of histone acetylation of the FoxO3a gene promoter and then FoxO3a gene expression, we performed in vitro experiments to observe the changes in the $\mathrm{H} 3$ and $\mathrm{H} 4$ acetylation levels of FoxO3a. The $\mathrm{H} 4$ acetylation of the FoxO3a promoter region was markedly decreased in the $\mathrm{H}_{2} \mathrm{O}_{2}$-exposed cells compared with that of the control group $(\mathrm{p}<0.01)$, whereas TSA elicited a significant increase in $\mathrm{H} 4$ acetylation of the 


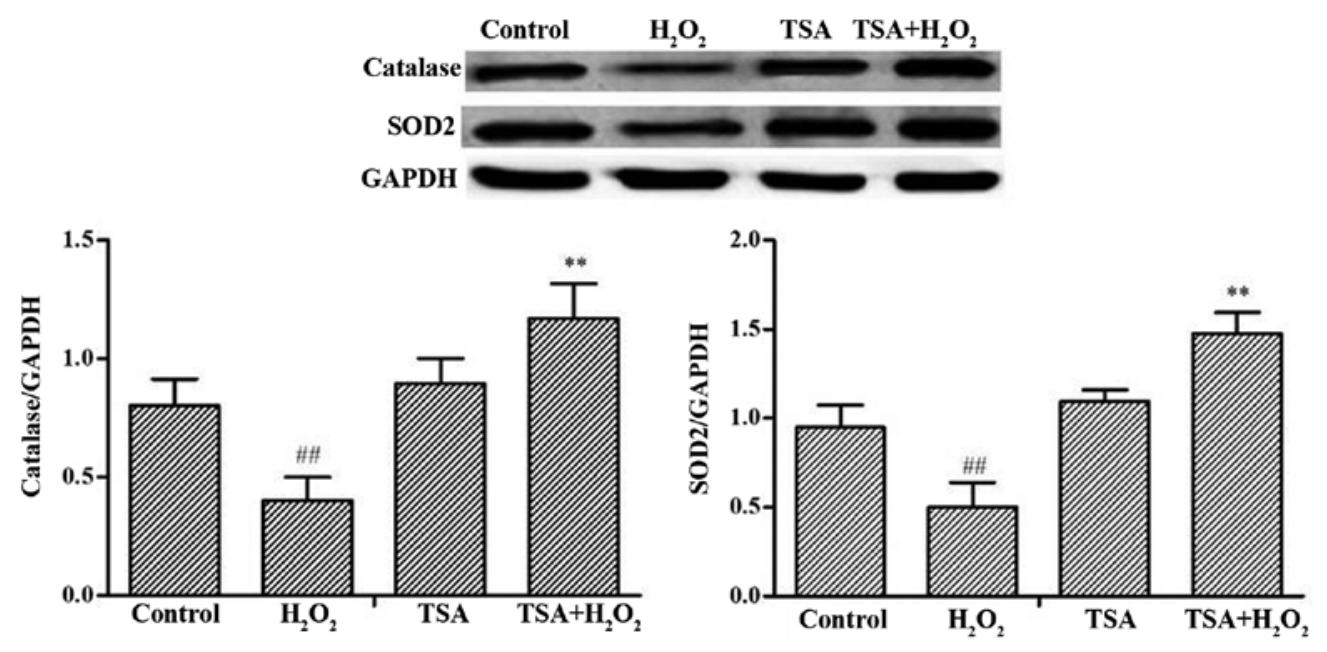

Figure 5. Effect of Trichostatin A (TSA) on superoxide diamutase 2 (SOD2) and catalase. Protein expression of SOD2 and catalase treated with/without $400 \mu \mathrm{M} \mathrm{H}_{2} \mathrm{O}_{2}$ for $2 \mathrm{~h}$ in the absence or presence of $50 \mathrm{nmol} / 1 \mathrm{TSA}$ in $\mathrm{H} 9 \mathrm{c} 2$ cells are shown. Mean $\pm \mathrm{SD} ;{ }^{*} \mathrm{p}<0.05$ and ${ }^{\# \#} \mathrm{p}<0.01 \mathrm{vs}$. control; ${ }^{* * *} \mathrm{P}<0.01 \mathrm{vs}$. $\mathrm{H}_{2} \mathrm{O}_{2}$.

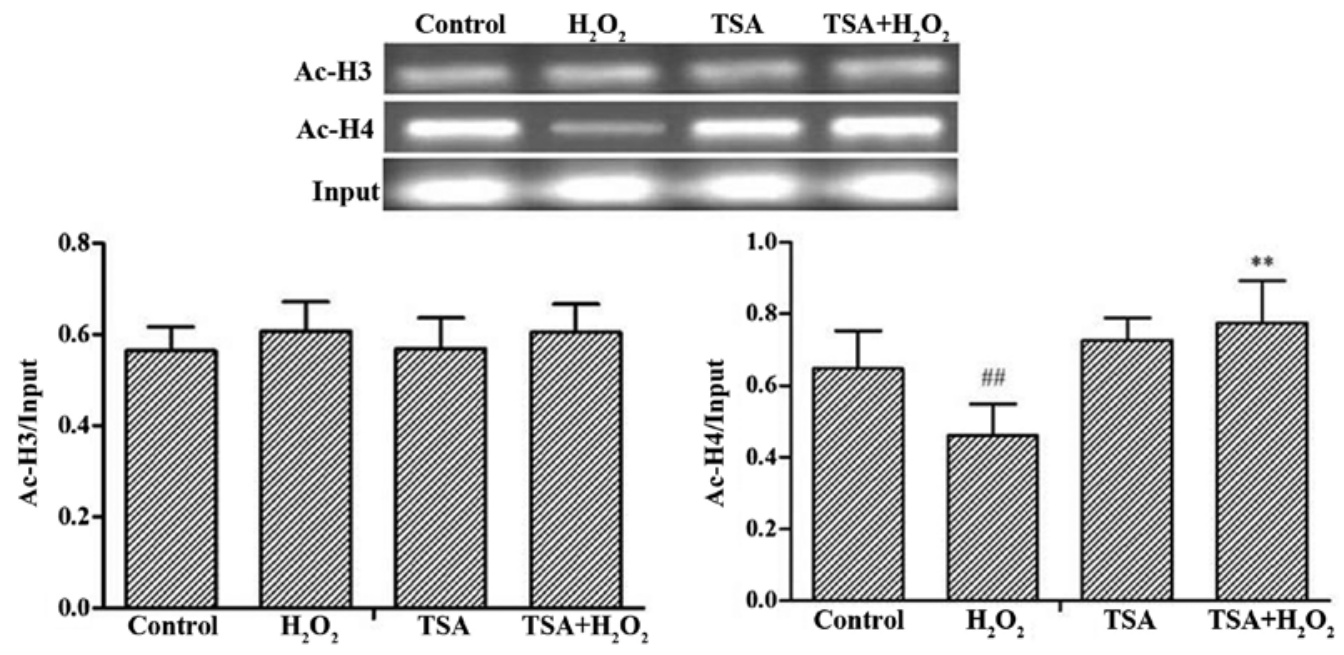

Figure 6. Effect of trichostatin A (TSA) on the acetylation levels of histone $\mathrm{H} 3$ and $\mathrm{H} 4$ in the promoter region of the forkhead box O3a (FoxO3a) gene. The acetylation levels of histone $\mathrm{H} 3$ and $\mathrm{H} 4$ in the promoter region of the FoxO3a gene following exposure or not to $400 \mu \mathrm{M} \mathrm{H}_{2} \mathrm{O}_{2}$ for $2 \mathrm{~h}$ in the absence or presence of $50 \mathrm{nmol} / 1 \mathrm{TSA}$ in $\mathrm{H} 9 \mathrm{c} 2$ cells are shown. Data are the means $\pm \mathrm{SD} ;{ }^{\# \#} \mathrm{p}<0.01 \mathrm{vs}$. controls; ${ }^{* *} \mathrm{p}<0.01 \mathrm{vs.} \mathrm{H}_{2} \mathrm{O}_{2}$-exposed group.

FoxO3a promoter region compared with that of the $\mathrm{H}_{2} \mathrm{O}_{2}$ group. The level of $\mathrm{H} 3$ acetylation of FoxO3a was not significantly altered (Fig. 6). The above-mentioned results thus indicate that TSA alters the $\mathrm{H} 4$ acetylation of the FoxO3a promoter region, thus affecting the expression of FoxO3a.

\section{Discussion}

The present study demonstrated that TSA attenuates myocardial injury mediated by oxidative stress in vivo and in vitro. This attenuation may be associated with the increased histone acetylation in the FoxO3a promoter region and the upregulation of the expression of FoxO3a, as well as the target proteins (SOD2 and catalase), which regulate the expression of ROS scavengers in response to ROS.

Oxidative stress is an important pathophysiological mechanism in myocardial injury (31). Oxidative stress means that the body suffers various harmful stimulations, disrupting the balance between the generation and clearance of ROS; the overproduction of ROS as byproducts by the mitochondria results in myocardial injury $(32,33)$. In this study, exposure to $\mathrm{H}_{2} \mathrm{O}_{2}$ at various concentrations for different periods of time in the $\mathrm{H} 9 \mathrm{c} 2$ cells decreased cell viability in a dose- and time-dependent manner (Fig. 1A). Intracellular ROS levels in the H9c2 cells exposed to $\mathrm{H}_{2} \mathrm{O}_{2}$ for different periods of time increased gradually (Fig. 1B). This may be associated with the downregulated expression of FoxO3a (Fig. 2). Depending on the different environment and cell types, FoxO3a plays an important role in lifespan extension, energy metabolism and resistance to oxidative stress $(34,35)$. FoxO3a also acts as the potential target for the treatment of several types of diseases (10). It has been demonstrated that FoxO3a plays an important role in maintaining cardiac function and antagonizing oxidative stress responses (36). Increasing the expression of FoxO3a reduces 
ROS and promotes cardiomyocyte survival (20). FoxO3a also upregulates the expression of ROS scavengers to clear ROS (30,37). Mitochondria are considered to be important cellular organelles as the source of $\operatorname{ROS}(38)$, and $\Delta \psi m$ is an important index maintaining mitochondrial function (39). A decrease in the $\Delta \psi m$ results in mitochondrial dysfunction, causing an increase in ROS generation. MDA, which is the final product of lipid peroxidation, can reflect the production of oxygen free radicals; the content can not only reflect the formation of oxygen free radicals in vivo, it can also reflect the severity of tissue damage caused by oxygen free radicals. SOD, which is the specific scavenger, can reduce free radical damage to myocardial cells. SOD plays an important role in the free radical scavenging system. The present study revealed that the downregulation of FoxO3a in $\mathrm{H} 9 \mathrm{c} 2$ cells was associated with the $\mathrm{H}_{2} \mathrm{O}_{2}$-induced increase in intracellular ROS levels, and reduced $\Delta \psi m$, and SOD2 and catalase levels. The opposite was observed following treatment with TSA (Figs. 3D and E, 4A and B and 5). Consistent with the experimental results obtained in vitro, TSA significantly reduced the MIS (Fig. 3A) and decreased the activities of serum CK, LDH and AST (Fig. 3B) in the rats. Moreover, TSA decreased the MDA level and increased SOD activity in the rats (Fig. 3C). These data suggest that TSA attenuates myocardial I/R-induced oxidative stress-related damage and upregulates the expression of FoxO3a, which is a possible mechanism ensuring the protective effects of TSA against I/R-induced myocardial injury (Fig. 4C).

Histone acetylation plays a pivotal role in the epigenetic modulation of gene expression and maintains a dynamic balance by affecting the activities of histone acetyltransferases and histone deacetylases (40). In most cases, the acetylation of transcription factors results in increasing their transactivation functions, principally by enhancing their DNA binding ability (41) and it has been shown that p300, an acetyltransferase, enhances the transcriptional activity of FoxO3a (42), reminding us that histone acetylation participates in FoxO3a regulation. Similar to a previous study showing that the acetylation level of the FoxO3a promoter region can be upgraded by HDAC inhibitors (21), we demonstrated that TSA reduced oxidative stress-induced myocardial injury by increasing the level of $\mathrm{H} 4$ acetylation of the FoxO3a promoter region, thereby enhancing the expression of FoxO3a (Fig. 6).

In conclusion, our data indicate that treatment with TSA attenuates oxidative stress-mediated myocardial damage by regulating the level of histone $\mathrm{H} 4$ acetylation in the promoter region of FoxO3a, and upregulating the expression of FoxO3a, SOD2 and catalase. Our findings provide a novel therapeutic strategy for TSA acting as a mediator of resistance to oxidative stress for myocardial protection.

\section{Acknowledgements}

This study was supported by the National Natural Science Foundation of China (grant no. 81570253).

\section{References}

1. Frank A, Bonney M, Bonney S, Weitzel L, Koeppen M and Eckle T: Myocardial ischemia reperfusion injury: From basic science to clinical bedside. Semin Cardiothorac Vasc Anesth 16: $123-132,2012$.
2. Cao J, Xie H, Sun Y, Zhu J, Ying M, Qiao S, Shao Q, Wu H and Wang C: Sevoflurane post-conditioning reduces rat myocardial ischemia reperfusion injury through an increase in NOS and a decrease in phopshorylated NHE1 levels. Int J Mol Med 36: 1529-1537, 2015 .

3. Jennings RB, Sommers HM, Smyth GA, Flack HA and Linn H: Myocardial necrosis induced by temporary occlusion of a coronary artery in the dog. Arch Pathol 70: 68-78, 1960.

4. Matsumoto T, Miura T, Miki T, Nishino Y, Nakamura Y and Shimamoto K: Does enhanced expression of the $\mathrm{Na}^{+}-\mathrm{Ca}^{2+}$ exchanger increase myocardial vulnerability to ischemia/reperfusion injury in rabbit hearts? Mol Cell Biochem 248: 141-147, 2003.

5. Wang M, Baker L, Tsai BM, Meldrum KK and Meldrum DR: Sex differences in the myocardial inflammatory response to ischemia-reperfusion injury. Am J Physiol Endocrinol Metab 288: E321-E326, 2005.

6. Qin C, Yap S and Woodman OL: Antioxidants in the prevention of myocardial ischemia/reperfusion injury. Expert Rev Clin Pharmacol 2: 673-695, 2009.

7. Sanada S, Komuro I and Kitakaze M: Pathophysiology of myocardial reperfusion injury: Preconditioning, postconditioning, and translational aspects of protective measures. Am J Physiol Heart Circ Physiol 301: H1723-H1741, 2011.

8. Guo J, Zheng D, Li HR, Zhang AD and Li ZC: Anti-apoptotic potency of TNFR:Fc gene in ischemia/reperfusion-induced myocardial cell injury. Inflammation 38: 664-671, 2015.

9. Zhou T, Chuang CC and Zuo L: Molecular characterization of reactive oxygen species in myocardial ischemia-reperfusion injury. BioMed Res Int 2015: 864946, 2015.

10. Nho RS and Hergert P: FoxO3a and disease progression. World J Biol Chem 5: 346-354, 2014.

11. Li M, Chiu JF, Mossman BT and Fukagawa NK: Downregulation of manganese-superoxide dismutase through phosphorylation of FOXO3a by Akt in explanted vascular smooth muscle cells from old rats. J Biol Chem 281: 40429-40439, 2006.

12. Dell'Aversana C, Lepore I and Altucci L: HDAC modulation and cell death in the clinic. Exp Cell Res 318: 1229-1244, 2012.

13. Grunstein M: Histone acetylation in chromatin structure and transcription. Nature 389: 349-352, 1997.

14. Shats I, Gatza ML, Liu B, Angus SP, You L and Nevins JR: FOXO transcription factors control E2F1 transcriptional specificity and apoptotic function. Cancer Res 73: 6056-6067, 2013.

15. Icardi L, De Bosscher K and Tavernier J: The HAT/HDAC interplay: Multilevel control of STAT signaling. Cytokine Growth Factor Rev 23: 283-291, 2012.

16. Cardinale JP, Sriramula S, Pariaut R, Guggilam A, Mariappan N, Elks CM and Francis J: HDAC inhibition attenuates inflammatory, hypertrophic, and hypertensive responses in spontaneously hypertensive rats. Hypertension 56: 437-444, 2010.

17. Usami M, Kishimoto K, Ohata A, Miyoshi M, Aoyama M, Fueda Y and Kotani J: Butyrate and trichostatin A attenuate nuclear factor kappaB activation and tumor necrosis factor alpha secretion and increase prostaglandin E2 secretion in human peripheral blood mononuclear cells. Nutr Res 28: 321-328, 2008

18. Lu JC, Chang YT, Wang CT, Lin YC, Lin CK and Wu ZS: Trichostatin A modulates thiazolidinedione-mediated suppression of tumor necrosis factor $\alpha$-induced lipolysis in 3T3-L1 adipocytes. PLoS One 8: e71517, 2013.

19. Yu L, Lu M, Wang P and Chen X: Trichostatin A ameliorates myocardial ischemia/reperfusion injury through inhibition of endoplasmic reticulum stress-induced apoptosis. Arch Med Res 43: 190-196, 2012.

20. Sengupta A, Molkentin JD, Paik JH, DePinho RA and Yutzey KE: FoxO transcription factors promote cardiomyocyte survival upon induction of oxidative stress. J Biol Chem 286: 7468-7478, 2011.

21. Shimazu T, Hirschey MD, Newman J, He W, Shirakawa K, Le Moan N, Grueter CA, Lim H, Saunders LR, Stevens RD, et al: Suppression of oxidative stress by $\beta$-hydroxybutyrate, an endogenous histone deacetylase inhibitor. Science 339: 211-214, 2013.

22. Li H, Liu Z, Wang J, Wong GT, Cheung CW, Zhang L, Chen C, $\mathrm{Xia} Z$ and Irwin MG: Susceptibility to myocardial ischemia reperfusion injury at early stage of type 1 diabetes in rats. Cardiovasc Diabetol 12: 133, 2013.

23. Bollini S, Cheung KK, Riegler J, Dong X, Smart N, Ghionzoli M, Loukogeorgakis SP, Maghsoudlou P, Dubé KN, Riley PR, et al: Amniotic fluid stem cells are cardioprotective following acute myocardial infarction. Stem Cells Dev 20: 1985-1994, 2011. 
24. Rukoyatkina N, Mindukshev I, Walter U and Gambaryan S: Dual role of the p38 MAPK/cPLA2 pathway in the regulation of platelet apoptosis induced by ABT-737 and strong platelet agonists. Cell Death Dis 4: e931, 2013.

25. Nechipurenko IV and Broihier HT: FoxO limits microtubule stability and is itself negatively regulated by microtubule disruption. J Cell Biol 196: 345-362, 2012.

26. Torres-Gonzalez M, Gawlowski T, Kocalis H, Scott BT and Dillmann WH: Mitochondrial 8-oxoguanine glycosylase decreases mitochondrial fragmentation and improves mitochondrial function in $\mathrm{H} 9 \mathrm{C} 2$ cells under oxidative stress conditions. Am J Physiol Cell Physiol 306: C221-C229, 2014

27. Akasaki Y, Alvarez-Garcia O, Saito M, Caramés B, Iwamoto Y and Lotz MK: FoxO transcription factors support oxidative stress resistance in human chondrocytes. Arthritis Rheumatol 66 3349-3358, 2014.

28. Huang W, Li G, Qiu J, Gonzalez P and Challa P: Protective effects of resveratrol in experimental retinal detachment. PLoS One 8: e75735, 2013

29. Lijnen PJ, van Pelt JF and Fagard RH: Downregulation of manganese superoxide dismutase by angiotensin II in cardiac fibroblasts of rats: Association with oxidative stress in myocardium. Am J Hypertens 23: 1128-1135, 2010.

30. Tan WQ, Wang K, Lv DY and Li PF: Foxo3a inhibits cardiomyocyte hypertrophy through transactivating catalase. J Biol Chem 283: 29730-29739, 2008.

31. Adluri RS, Thirunavukkarasu M,Zhan L, Maulik N, Svennevig K, Bagchi M and Maulik G: Cardioprotective efficacy of a novel antioxidant mix VitaePro against ex vivo myocardial ischemiareperfusion injury. Cell Biochem Biophys 67: 281-286, 2013.

32. Chen Q, Moghaddas S, Hoppel CL and Lesnefsky EJ: Reversible blockade of electron transport during ischemia protects mitochondria and decreases myocardial injury following reperfusion. J Pharmacol Exp Ther 319: 1405-1412, 2006.
33. Ji L, Fu F, Zhang L, Liu W, Cai X, Zhang L, Zheng Q, Zhang H and Gao F: Insulin attenuates myocardial ischemia/reperfusion injury via reducing oxidative/nitrative stress. Am J Physiol Endocrinol Metab 298: E871-E880, 2010

34. Salih DA and Brunet A: FoxO transcription factors in the maintenance of cellular homeostasis during aging. Curr Opin Cell Biol 20: 126-136, 2008.

35. Zeng Y, Cheng L, Chen H, Cao H, Hauser ER, Liu Y, Xiao Z, Tan Q, Tian XL and Vaupel JW: Effects of FOXO genotypes on longevity: A biodemographic analysis. J Gerontol A Biol Sci Med Sci 65: 1285-1299, 2010.

36. Ronnebaum SM and Patterson C: The FoxO family in cardiac function and dysfunction. Annu Rev Physiol 72: 81-94, 2010.

37. Kops GJ, Dansen TB, Polderman PE, Saarloos I, Wirtz KW, Coffer PJ, Huang TT, Bos JL, Medema RH and Burgering BM: Forkhead transcription factor FOXO3a protects quiescent cells from oxidative stress. Nature 419: 316-321, 2002.

38. Paradies G, Petrosillo G, Paradies V and Ruggiero FM: Mitochondrial dysfunction in brain aging: Role of oxidative stress and cardiolipin. Neurochem Int 58: 447-457, 2011.

39. Wang L, Lu K, Hao H, Li X, Wang J, Wang K, Wang J, Yan Z, Zhang S, Du Y, et al: Decreased autophagy in rat heart induced by anti- $\beta 1$-adrenergic receptor autoantibodies contributes to the decline in mitochondrial membrane potential. PLoS One 8: e81296, 2013

40. Peserico A and Simone C: Physical and functional HAT/HDAC interplay regulates protein acetylation balance. J Biomed Biotechnol 2011: 371832, 2011.

41. Chen H, Tini M and Evans RM: HATs on and beyond chromatin. Curr Opin Cell Biol 13: 218-224, 2001.

42. Motta MC, Divecha N, Lemieux M, Kamel C, Chen D, Gu W, Bultsma Y, McBurney M and Guarente L: Mammalian SIRT1 represses forkhead transcription factors. Cell 116: 551-563, 2004. 